\title{
Lawsuits on malpractice related to spinal anesthesia and intracranial hematomas: a study of three cases
}

\begin{abstract}
Spinal anesthesia is routinely used in anesthesia with a continued popularity due to the safety, effectiveness and efficiency of this technique. The increased number of ambulatory surgical procedures has resulted in more frequent use of it. Intracranial hematomas are rare but serious complications of spinal anesthesia; including intracranial acute or chronic subdural hematomas; subarachnoid and intraventricular hematomas and as spinal subarachnoid, subdural or epidural hematomas. In this paper, three cases of intracranial hematomas related to spinal anesthesia that were subjected to lawsuits based on claims of a medical malpractice are presented.
\end{abstract}

Keywords: complication, dural puncture, intracranial hematoma, malpractice, spinal anesthesia, subdural hematoma

\author{
Volume 6 Issue 3 - 2018
}

\author{
Şanyuz ÖK,' Eraslan BȘ, ${ }^{2}$ Demircan YT, ${ }^{3}$ \\ Altınok $M,{ }^{2}$ Aslan NA, ${ }^{2}$ Fuat Kılıç F, Çakı İE, ${ }^{2}$ \\ Hakan T, ${ }^{4}$ Kınoğlu K, I Yorulmaz AC ${ }^{2}$ \\ 'Council of Forensic Medicine, Justice Ministry, Turkey \\ 2Department of Forensic Medicine, İstanbul University, Turkey \\ ${ }^{3}$ İstanbul University, İnstute of Forensic Medicine, Turkey \\ ${ }^{4}$ Neurosurgeon, Kolan International Hospital,Turkey
}

Correspondence: Kubilay Kınoğlu, The Council of Forensic Medicine, Fevzi Çakmak Mahallesi Sanayi Caddesi, Kımız Sokak No:I Bahçelievler/İSTANBUL 34 | 96, Turkey, Tel +905052459028, Email dr.kubilaykinoglu@gmail.com

Received: May 06, 2018 | Published: May 21, 2018

\section{Introduction}

Spinal anesthesia is routinely used in anesthesia with a continued popularity due to the safety, effectiveness and efficiency of this technique. ${ }^{1}$ The increased number of ambulatory surgical procedures has resulted in more frequent use of it. Spinal anesthesia is the most widely used method of anaesthesia and analgesia in obstetrics since $1950 .^{2}$ Intracranial hematomas are rare but serious complications of spinal anesthesia. ${ }^{3}$ These hematomas can be seen as intracranial acute $^{4,5}$ or chronic $^{6,7}$ subdural hematomas; subarachnoid and intraventricular hematomas, ${ }^{8,9}$ and as spinal subarachnoid, subdural, ${ }^{9}$ or epidura $1^{10}$ hematomas. While acute intracranial hematomas can be located unilateral hemispheric, ${ }^{11,12}$ the chronic hematomas can be seen unilateral, ${ }^{6,13}$ bilateral ${ }^{14}$ hemispheric or interhemispheric. ${ }^{15}$ Although the intracranial complications of spinal anesthesia are known very well since many years, they do not have any excuse from being a subject of medical malpractice. In this paper, three cases of intracranial hematomas related to spinal anesthesia that were subjected to lawsuits based on claims of a medical malpractice are presented.

\section{Materials and methods}

These three cases investigated here were from three different medical centers and the spinal anesthetic procedures were done by three different anesthesia teams. All hospital records of all three patients were analyzed meticulously. The preparation of the patient by means of routine laboratory blood tests including platelet count, prothrombin time and activated prothromboplastin time, the choice of adequate anesthesia technique and informed patient consent for anesthesia, the perioperative (pre-intra and postoperative) records of anesthetic application were the main milestones for the initial anesthetic application. The detection of the information of the patients for being alert to the possible complications of spinal anesthesia was particularly important. The second phase of the investigation was about the management of the complication. The data of the evaluation of the patient's signs and symptoms, clinical, laboratory and radiological examinations were carefully explored. The evidence of determining and conducting of appropriate treatment of the complication were analyzed.

\section{Patients}

\section{Report of cases}

Case 1: A 28-year-old female patient had an uneventful cesarean section under spinal anesthesia to deliver a baby for prolonged and obstructed labor. The patient was admitted with a mild headache on the third day following delivery which was assumed to be a PDPH (postdural puncture headache) because it was more intense in the sitting position. She was treated with medically including "epidural patch therapy". After a month, she was readmitted with severe headache. A computerized cranial tomography $(\mathrm{CT})$ revealed bilateral subdural hematoma $-4 \mathrm{~mm}$ at right and $17 \mathrm{~mm}$ at left hemisphere. She had a left sided chronic subdural hematoma evacuation operation.

Case 2: A 31-year-old female patient was admitted to hospital with a generalized seizure attack in the 4th postpartum day. She had delivered a baby with a cesarean section under spinal anesthesia and had a severe headache for 2 days that was ended with seizure attack. A computerized cranial tomography showed a right sided subacute hemispheric subdural hematoma that required hematoma evacuation.

Case 3: A 77-year-old man patient had a urological operation under spinal anesthesia. The patient was under thromboprophlactic treatment previous and during surgery. Preoperative laboratory blood tests, including platelet count, prothrombin time and activated prothromboplastin time, were normal. The patient received no anticoagulants in the last one week prior to operation. The patient worsened neurologically after surgery. A CT treatment showed a right parietal acute subdural hematoma that required evacuation.

\section{Results}

All cases had preoperative evaluation by an anesthetist; by means of clinic and laboratory tests. All parameters of the patients were within normal limits of their own laboratories. The third case was 
examined and prepared for spinal anesthesia and under hematologic consultations. Preoperative informed patient consent for anesthesia -apart from surgical one, the detailed intra and postoperative anesthesia records of the patient including the anesthetic drugs, spinal anesthetic kit and course of anesthesia were registered. All the patients were under responsibility of a staff anesthetist and the procedures were done by them. According the files, only in case three was the lumber puncture attempted more than one, twice.

\section{Discussion}

Medical claims related to clinical applications are increasing in recent years. ${ }^{16}$ Complications of spinal anesthesia are among the subjects of these legal issues..$^{10,17,18}$ In this study, we discussed the medico-legal aspect of a special theme of a clinical practice: "spinal anesthesia and intracranial hematoma". "Medical malpractice" was described by the $44^{\text {th }}$ World Medical Assembly Marbella, Spain, September 1992 and rescinded at the WMA General Assembly, Santiago 2005: "the physician's failure to conform to the standard of care for treatment of the patient's condition, or a lack of skill, or negligence in providing care to the patient, which is the direct cause of an injury to the patient." The basic points of this subject are the physician's failure and/or negligence. All kinds of situations that cause suffering/injuring to the patient related with medical applications are untoward result; if this untoward result emerges from the physician's failure and/or negligence then, it is malpractice. Untoward result or complication defined as the injury occurring in the course of medical treatment which could not be foreseen and was not the result of any lack of skill or knowledge on the part of the treating physician is an untoward result, for which the physician should not bear any liability. All the cases of this study could be exposed to dural puncture during spinal anesthesia for their operations. Dural puncture and PDPH are common but serious complication of spinal anesthesia. ${ }^{19}$ Dural puncture during spinal anesthesia even cause intracranial hematoma. ${ }^{7}$ Zeidan et al. ${ }^{13}$ reported 21 cases of intracranial hematoma following spinal anesthesia in obstetric and non-obstetric patients. There are many published scientific paper. ${ }^{3-8,11,12,14,15,20}$ in the literature reporting this situation as complication; so, intracranial hemorrhages of these patients might be handling as an untoward complication of spinal anesthesia.

In the first case the patient was treated with spinal epidural patch when she was admitted with headache in the third postpartum day. Spinal epidural patch is a gold standard for treatment of PDPH. ${ }^{19}$ There was no obvious evidence of negligence in management of the patient. The headache was postural and no neurological symptom was detected. LP, prolonged and non-postural PDPH, and development of neurological symptoms should be regarded as a warning sign of an intracranial hematoma and prompt immediate diagnosis and treatment; otherwise, the case should be a subject of negligence. The other two cases were evaluated promptly for their neurological symptoms. One had seizure which is a very important symptom deserving a carefully handling, the other was had worsened immediately following surgery. Both cases were investigated appropriately and directed to neurosurgery for treatment.

Another point of this subject is the issue of informed consent. The anesthesia consent should stress the risks, benefits, and alternatives unique to anesthesia which can be very different from surgical risks in detail. ${ }^{20}$ In all of these cases, informed consents of the patients were obtained previous the anesthetic applications, the patients and their legal representatives were aware of the spinal anesthesia. The preparation of the patient for any clinical procedure, in means of anesthesia and/or surgery is also very important for avoiding any unpleasant situation may be lead to issue of malpractice. As in the third case, the preoperative condition of the patient, the use of drugs as antiaggregants or anticoagulants and the laboratory blood tests, including platelet count, prothrombin time and activated prothromboplastin time should be evaluated meticulously.

\section{Conclusion}

In conclusion, the cases of intracranial hemorrhages following spinal anesthesia investigated in this paper are accepted as complication of the anesthesia. Obeying the rules mentioned here may be prevent the practitioner to be faced with being an issue of a lawsuit of malpractice.

\section{Acknowledgements}

None.

\section{Conflict of interest}

Authors declare that there is no conflict of interest

\section{References}

1. Mordecai MM, Brull SJ. Spinal anesthesia. Current Opinion in Anesthesiology. 2005;18(5):527-33.

2. Morgan P. Spinal anaesthesia in obstetrics. Canadian Journal of Anaesthesia. 1995;42(12):1145-63.

3. Amorim JA, Remigio DS, Damazio Filho O, et al. Intracranial subdural hematoma post-spinal anesthesia: report of two cases and review of 33 cases in the literature. Rev Bras Anestesiol. 2010;60(6):620-9.

4. Abbinante C, Lauta E, Di Venosa N, et al. Acute subdural intracranial hematoma after combined spinal-epidural analgesia in labor. Minerva Anestesiol. 2010;76(12):1091-4.

5. Kayacan N, Arici G, Karsli B, et al. Acute subdural haematoma after accidental dural puncture during epidural anaesthesia. Int J Obstet Anesth. 2004;13(1):47-9.

6. Acharya R. Chronic subdural haematoma complicating spinal anaesthesia. Neurological Sciences. 2005;25(6):348-50.

7. Ozdemir N, Ari MK, Gelal MF, et al. Intracranial chronic subdural haematoma as a complication of epidural anesthesia. Turk Neurosurg. 2009;19(3):285-7.

8. Lee SJ, Lin YY, Hsu CW, et al. Intraventricular hematoma, subarachnoid hematoma and spinal epidural hematoma caused by lumbar puncture: an unusual complication. Am J Med Sci. 2009;337(2):143-5.

9. Rocchi R, Lombardi C, Marradi I, et al. Intracranial and intraspinal hemorrhage following spinal anesthesia. Neurol Sci. 2009;30(5):393-6.

10. Lee LA, Posner KL, Domino KB, et al. Injuries associated with regional anesthesia in the 1980s and 1990s: a closed claims analysis. Anesthesiology. 2004;101(1):143-52.

11. Dawley B, Hendrix A. Intracranial subdural hematoma after spinal anesthesia in a parturient. Obstet Gynecol. 2009;113(2 Pt 2):570-3.

12. Yildirim GB, Colakoglu S, Atakan TY, et al. Intracranial subdural hematoma after spinal anesthesia. Int J Obstet Anesth. 2005;14(2):159-62.

13. Zeidan A, Farhat O, Maaliki H, et al. Does postdural puncture headache 
left untreated lead to subdural hematoma? Case report and review of the literature. Int J Obstet Anesth. 2006;15(1):50-8.

14. Cohen JE, Godes J, Morales B. Postpartum bilateral subdural hematomas following spinal anesthesia: case report. Surg Neurol. 1997;47(1):6-8.

15. Liang MY, Pagel PS. Bilateral interhemispheric subdural hematoma after inadvertent lumbar puncture in a parturient. Can $J$ Anaesth. 2012;59(4):389-93.

16. World Medical Association Statement on Medical Malpractice. 2016.

17. Kiuchi A, Matsumura Y, Makino Y, et al. Analysis of lawsuits on malpractice related to spinal anesthesia in Japan--change in the causes of anesthetic malpractice related to judicial precedents. Leg Med. 2009;11(1):S370-1.
18. Ozdemir MH, Cekin N, Can IO, et al. Malpractice and system of expertise in anaesthetic procedures in Turkey. Forensic Sci Int. 2005;153(2-3):1617.

19. Sachs A, Smiley R. Post-dural puncture headache: the worst common complication in obstetric anesthesia. Semin Perinatol. 2014;38(6):386-94.

20. Pascarella MR, Walls JD, Liu R, Chen L. Anesthesia Providers are Obligated to Give Patients the Alternatives to General Anesthesia when Obtaining Informed Consent. Transl Perioper Pain Med. 2014;1(2):5-8. 